\title{
Seed development in Paeonia ostii (Paeoniaceae), with particular reference to embryogeny
}

Keliang Zhang ${ }^{1,2}$, Weizhang Cao ${ }^{1,2}$, Jerry M. Baskin³, Carol C. Baskin³,4 Jing Sun 1,2, Linjun Yao ${ }^{1,5}$ and Jun Tao ${ }^{1,2^{*}}$

\begin{abstract}
Background: Seeds of Paeonia ostii have been proposed as a source of raw material for the production of edible oil; however, lack of information about the developmental biology of the seeds hampers our ability to use them. Our aim was to investigate development of the seed coat, endosperm and embryo of $P$. ostii in relation to timing of accumulation of nutrient reserves from pollination to seed maturity. Ovules and developing seeds of $P$. ostii were collected at various stages of development from zygote to maturity. Seed fresh mass, dry mass, germination, moisture, soluble sugars, starch, protein and oil content were determined. Ontogeny of seeds including embryo, endosperm and seed coat were analyzed histologically.

Results: The ovule of P. ostii is anatropous, crassinucellate and bitegmic. The zygote begins to divide at about 5 days after pollination (DAP), and the division is not accompanied by cell wall formation. By 25 DAP, the proembryo begins to cellularize. Thereafter, several embryo primordia appear at the surface of the cellularized proembryo, but only one matures. Endosperm development follows the typical nuclear type. The seed coat is derived from the outer integument. During seed development, soluble sugars, starch and crude fat content increased and then decreased, with maximum contents at 60,80 and 100 DAP, respectively. Protein content was relatively low compared with soluble sugars and crude fat, but it increased throughout seed development.
\end{abstract}

Conclusions: During seed development in P. ostii, the seed coat acts as a temporary storage tissue. Embryo development of P. ostii can be divided into two stages: a coenocytic proembryo from zygote $(n+n)$ that degenerates and a somatic embryo from peripheral cells of the proembryo $(2 n \rightarrow 2 n)$. This pattern of embryogeny differs from that of all other angiosperms, but it is similar to that of gymnosperms.

Keyword: Paeonia ostia, plant embryology, seed anatomy, seed development, storage reserves

\section{Background}

The seed development process in angiosperms usually is initiated by double fertilization [1]. That is, one sperm cell fertilizes a haploid egg, and the other sperm cell fertilizes a homodiploid central cell in the ovule, leading to production of a diploid embryo and triploid endosperm

\footnotetext{
*Correspondence: taojun@yzu.edu.cn

1 College of Horticulture and Plant Protection, Yangzhou University,

Yangzhou 225009, China

Full list of author information is available at the end of the article
}

[1-3]. The seed coat originates entirely from maternal tissues and is derived from the inner and/or outer layers of the integument [4]. The seed coat provides a pathway for movement of carbon and nitrogen from organ sources to the embryo and endosperm. It also protects the embryo and endosperm, thereby increasing the chance a seed will reach maturity and help establish the next generation [3]. If fertilization fails, the ovule degenerates rapidly, which insures that nutrients invested in the aborted seed are recycled [3]. Many storage compounds accumulate as seeds develop, including carbohydrates (starch), proteins 
and lipids [4]. These reserves provide about $70 \%$ of the calories consumed by humans worldwide. Thus, understanding seed development is of major economic importance and could be valuable information for improvement of seed yield and seed nutritive values [1].

The genus Paeonia (Paeoniaceae) is one of the world's most ancient flowering plant groups [5]. It consists of ca. 35 species of shrubs and perennial herbs that are grown extensively across five disjunct zones of the northern hemisphere: eastern Asia, central Asia, western Himalayas, Mediterranean region and Pacific northwest North America [6]. Members of this genus are widely cultivated for their ornamental and medicinal values $[7,8]$. Especially in China, species of tree peony are known as the "king of the flowers", and they are planted as major garden plants with numerous cultivars and hybrids [7]. Further, many peony species, such as P. lactiflora, $P$. ostii and $P$. veitchii, contain chemical compounds with pharmacological activities, such as albiflorin, oxypaeoniflorin, paeoniflorin and paeonol that are unique to this genus [7, 8]. In traditional Chinese medicine, they are prescribed for women's diseases (dysmenorrhoea or menorrhagia) and for various painful inflammatory conditions such as cholecystitis [8].

In recent years, seeds of tree peonies have been proposed as a source of raw material for edible oil [9], and oilseed peony has become a newly-emergent woody plant oil crop. Seeds of various species and varieties of tree peony contain $24.0-37.8 \%$ oil; $>90 \%$ of the fatty acids, such as $\alpha$-linolenic, linoleic and oleic acids, are unsaturated. These fatty acids can provide humans several health benefits, such as lowering blood pressure, inhibiting platelet aggregation during blood clotting and reducing the overall risk for cardiovascular diseases $[10,11]$.

Paeonia ostii is one of the main species proposed for oil seed production. However, tapping of its potential for oil production is hampered by a lack of basic information regarding the developmental biology of the seeds. For example, very little is known about development of the seed coat, endosperm and embryo in relation to timing of accumulation of nutrient reserves, especially fatty acids.

To date, studies of $P$. ostii seeds have focused on seed dormancy and germination [12-14], seed yield, nutrition analysis [15] and fatty acid composition [16, 17]. Although there are some reports dealing with seed development in $P$. ostii $[15,18]$, they mainly have focused on fatty acid composition and changes in storage reserves of the seeds, and the precise temporal and spatial patterns of formation of the seed coat, endosperm and embryo are lacking. For example, Li et al. [18] divided the development of $P$. ostii seeds into three stages: (i) initial growth (0 to 30 DAP) with low fatty acid accumulation, (ii) rapid growth (31-90 DAP) with accumulation of fatty acid and (iii) maturation (91-100 DAP) with a decrease in fatty acid content. However, fatty acid accumulation alone does not fully characterize the whole seed development process [18]. Han et al. [15] also divided the development of $P$. ostii seeds into three stages: (i) rapid growth (0 to 70 DAP), (ii) slow growth (71-98 DAP) and (iii) maturation (99-112 DAP). However, their first two samples were taken from 14 and $28 \mathrm{DAP}$, and they did not recognize the slow growth before 20 DAP [15]. In the field, no embryo and endosperm could be seen with the naked eye 40-50 DAP; instead, only the seed coat could be seen. We ask: what happens in the seeds during these stages of growth? For example, during which growth stage(s) is (are) seed coat, embryo and endosperm development completed, and when does accumulation of storage reserves reach its peak?

Our aim was to obtain a detailed picture of seed development of $P$. ostii from pollination to maturity in relation to timing of accumulation of various storage compounds. Thus, for various stages of seed development we collected cytological data on embryo, endosperm and seed coat; soluble sugars, starch, protein and crude fat content; and seed germinability. This information will help identify the stages in seed/endosperm development that are the most critical in terms of oil accumulation and thus potentially assist in development of high oil yielding varieties of $P$. ostii.

Further, the availability and accessibility of draft genome sequences for Paeonia species [19] and of a flurry of transcriptomic analyses [20,21] were designed to define the proteomic changes associated with seed development and the expression patterns of genes involved in the synthesis of fatty acids in Paeonia seeds. Nevertheless, because information related to the exact spatial and temporal patterns involved in the formation of the seed coat, embryo and endosperm is lacking, the biological meaning associated with some transcriptomic and proteomic data remains uncertain. This uncertainty usually occurs because tissue samples used in these studies are selected without considering the seed developmental stage, or seed tissues are not separated [21].

\section{Results}

\section{Morphological changes in seeds during development}

In the early stages of development, major changes occurred in the shape of $P$. ostii seeds. At 0 DAP, the ovules are bullet-shaped, but they were rhombus-shaped at 10 DAP. At 20 DAP, seeds were oval, globose or ovoidglobose, and these shapes persisted until 125 DAP, at the time of seed dispersal (Fig. 1). The color of developing seeds gradually darkened over time, with seeds at $0-50$ DAP ivory white and those at 60-90 DAP light yellow. At 100 DAP, a dark-brown tinge appeared on the side 


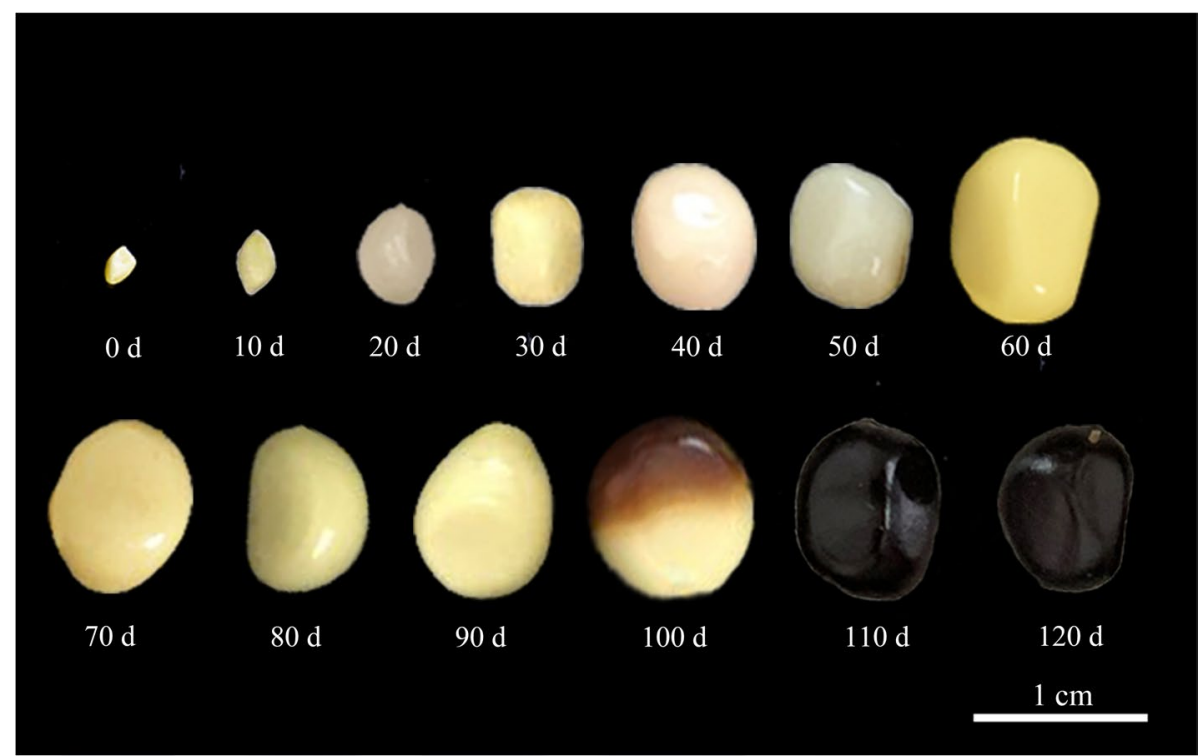

Fig. 1 Changes in size and color of seeds (ovule to maturity) of Paeonia ostii during development

opposite the hilum in most seeds, and the color gradually spread throughout the seed. The entire seed coat was black by 110 DAP. From 0-65 DAP, seed size gradually increased with seed length $>$ width $>$ thickness, remained constant between 65 and 100 DAP and decreased slightly between 100 and 120 DAP (Fig. 2a; Table S1).

\section{Mass and water content of developing seeds}

During seed development, seed dry mass gradually increased, and it peaked at 100 DAP, when the seeds became physiologically mature (Fig. 2b; Table S1). However, from 5-65 DAP fresh seed mass gradually increased; at $65 \mathrm{DAP}$, fresh mass peaked $(0.67 \pm 0.07 \mathrm{~g})$. Fresh seed mass remained stable until 100 DAP, when it was $0.55 \pm 0.01 \mathrm{~g}$. From 100 to $125 \mathrm{DAP}$, fresh seed mass decreased (Fig. 2b; Table S1). At 125 DAP, fresh seed mass was $0.46 \pm 0.02 \mathrm{~g}$. However, seed water content decreased throughout the period of development (Fig. 2b). Water content at 5 DAP was $83.16 \pm 2.07 \%$, and it declined to $41.78 \pm 1.27 \%$ at $110 \mathrm{DAP}$ and $34.85 \pm 1.32 \%$ at $125 \mathrm{DAP}$ (Fig. 2b; Table S1).

\section{Embryo morphology and germinability of developing seeds}

At 60-65 DAP, the embryo was rod-shaped, and the cotyledons were not fully developed (Fig. 3). At 70 DAP, the cotyledons started to enlarge, and they developed into fan-shaped cotyledons by 80 DAP. In addition, embryo size gradually increased. At 60 DAP, length of the embryo was $1.61 \pm 0.08 \mathrm{~mm}$, and at 110
DAP it was $3.29 \pm 0.19 \mathrm{~mm}$. In addition, embryo color changed during seed development. At 60 DAP, the cotyledons were translucent and radicles yellow. At 65-85, the whole embryo was yellow and at 90-110 DAP white.

The developing seeds became germinable at 60-70 DAP. No seeds germinated before 60 DAP, while at 70 DAP 33\% did so. Germination increased gradually to the maximum $(96 \pm 2.6 \%)$ by 110 DAP (Fig. 4). Furthermore, as seeds developed germination rate (speed) increased. At $70 \mathrm{DAP}$, seeds required about 80 days for radicle emergence, while at 120 DAP they required less than 30 days.

\section{Soluble sugars, starch, protein and crude fat content of developing seeds}

Storage reserves changed drastically during seed development (Fig. 5; Table S1). Soluble sugars, starch and crude fat content increased and then decreased, but the date they reached their maximum content differed. Maximum content of soluble sugars was $232 \mathrm{mg} / \mathrm{g}$ at 60 DAP, after which it decreased sharply, and by 120 DAP maximum sugar content was only $43 \mathrm{mg} / \mathrm{g}$. Starch content reached a maximum of $73 \mathrm{mg} / \mathrm{g}$ at $80 \mathrm{DAP}$, after that it decreased to $56 \mathrm{mg} / \mathrm{g}$ by 120 DAP. Maximum crude fat content was $212 \mathrm{mg} / \mathrm{g}$ at $100 \mathrm{DAP}$, after which it decreased slightly; at 120 DAP, it was $193 \mathrm{mg} / \mathrm{g}$. Protein content was relatively low compared with crude fat, soluble sugars and starch, but it increased throughout seed development; at 120 DAP, it was only $40 \mathrm{mg} / \mathrm{g}$. 


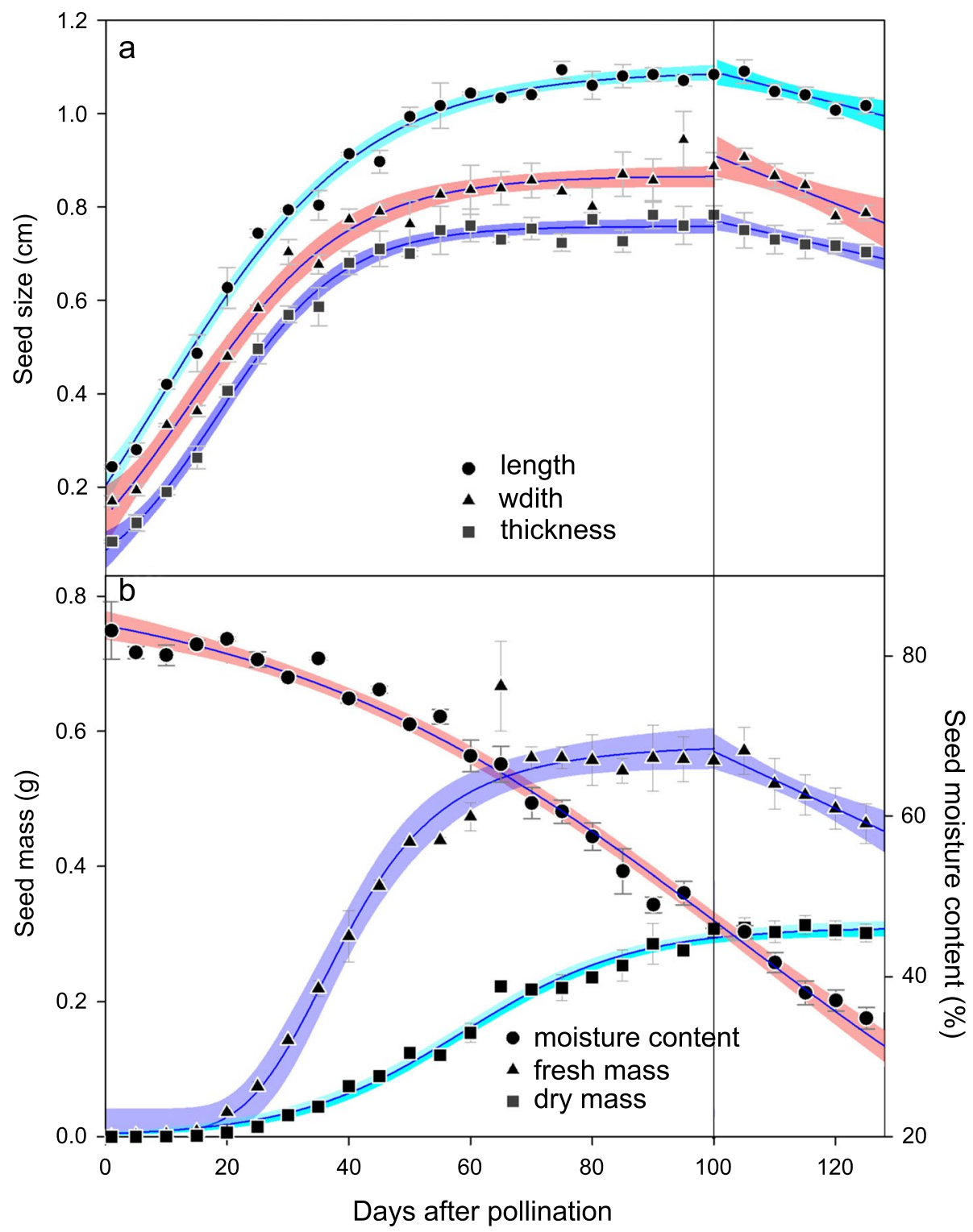

Fig. 2 Changes in length, width, thickness, moisture content, fresh mass and dry mass of Paeonia ostii seeds during development. (a) Seed length, width and thickness (mean \pm s.e.); (b) moisture content, fresh mass and dry mass (mean \pm s.e.). Solid lines are regression curves and color bands $95 \%$ confidence intervals

\section{Anatomical changes in seeds during development}

The ovule of $P$. ostii is anatropous, crassinucellate and bitegmic (Fig. 6a). The inner integument is composed of 3-4 layers of parenchyma cells, while the outer integument has 14-20 layers of parenchyma cells (Fig. 6a). The mature embryo sac is elongated and located in the center of the ovule, and it is comprised of an egg cell, two synergid cells, three antipodal cells and two polar nuclei (Fig. 6a and b. antipodals not shown). Since the egg and two synergid cells are not in the same plain, they cannot all be shown in the same slide. At 1-5 DAP, the sperm nucleus enters the egg with assistance from one of the synergid cells (Fig. 6b shows two sperm nuclei in synergid).

After fertilization, the zygote is relocated from the micropyle area to the center of the embryo sac. The zygote begins to divide about 5 DAP, and the division is not accompanied by cell wall formation. Instead, the zygote divides repeatedly and forms a coenocytic proembryo, in which a large vacuole was observed (Fig. 6c). Both synergids are sometimes observed, and one of them may persist until the proembryo reaches a fairly large 


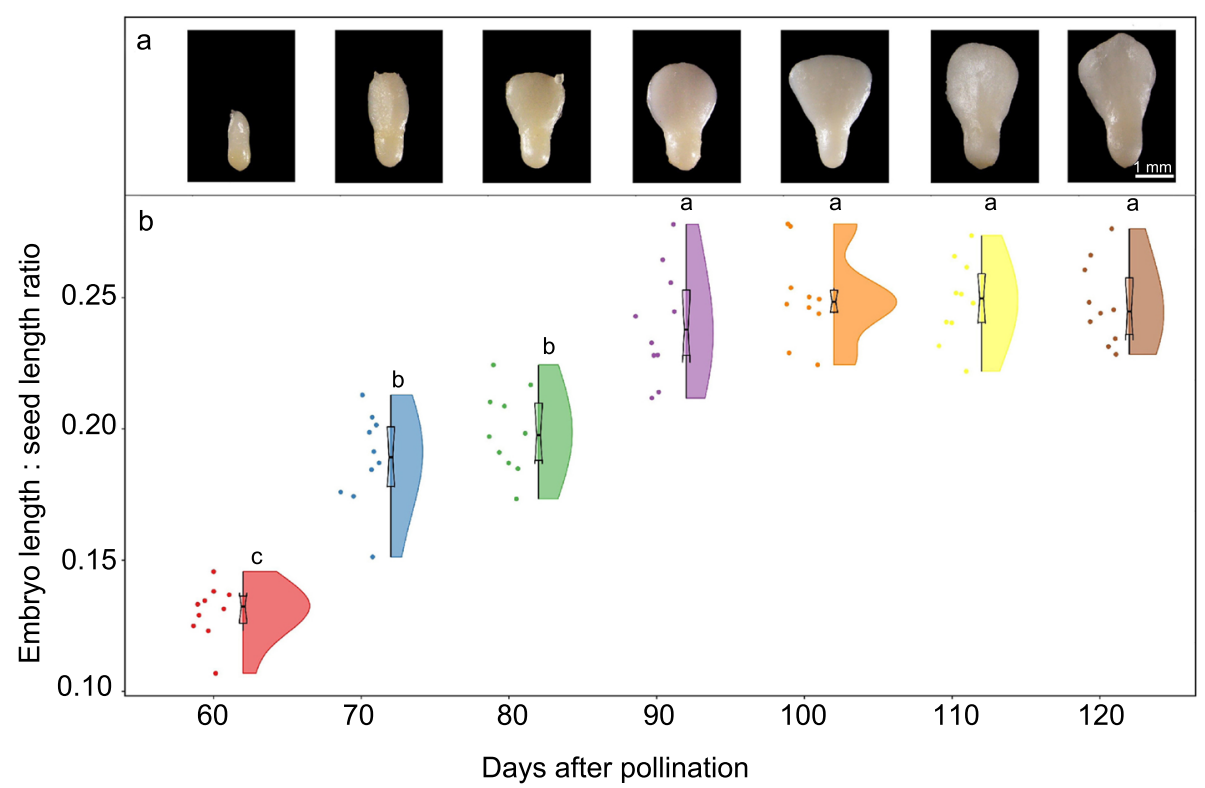

Fig. 3 (a) Embryo development (ovule to maturity) morphology and (b) raincloud plot showing embryo length: seed length ratios in developing seeds of Paeonia ostii. The raincloud plot combines an illustration of data distribution (the 'cloud') with raw point data (the 'rain'). That is, the colored area (cloud) represents data distribution (the more data points in a specific range, the larger the cloud is for that range). The black boxplot is the interquartile range, middle line the median value and thin line extending from the box the upper (max) and lower (min) adjacent values in the data; the dots (rain) are raw point data. Points are random values assigned to the dots to separate them so that they are not plotted directly on top of each other. Different letters indicate significant differences in embryo length: seed length ratios among different days after pollination $(P<0.05)$

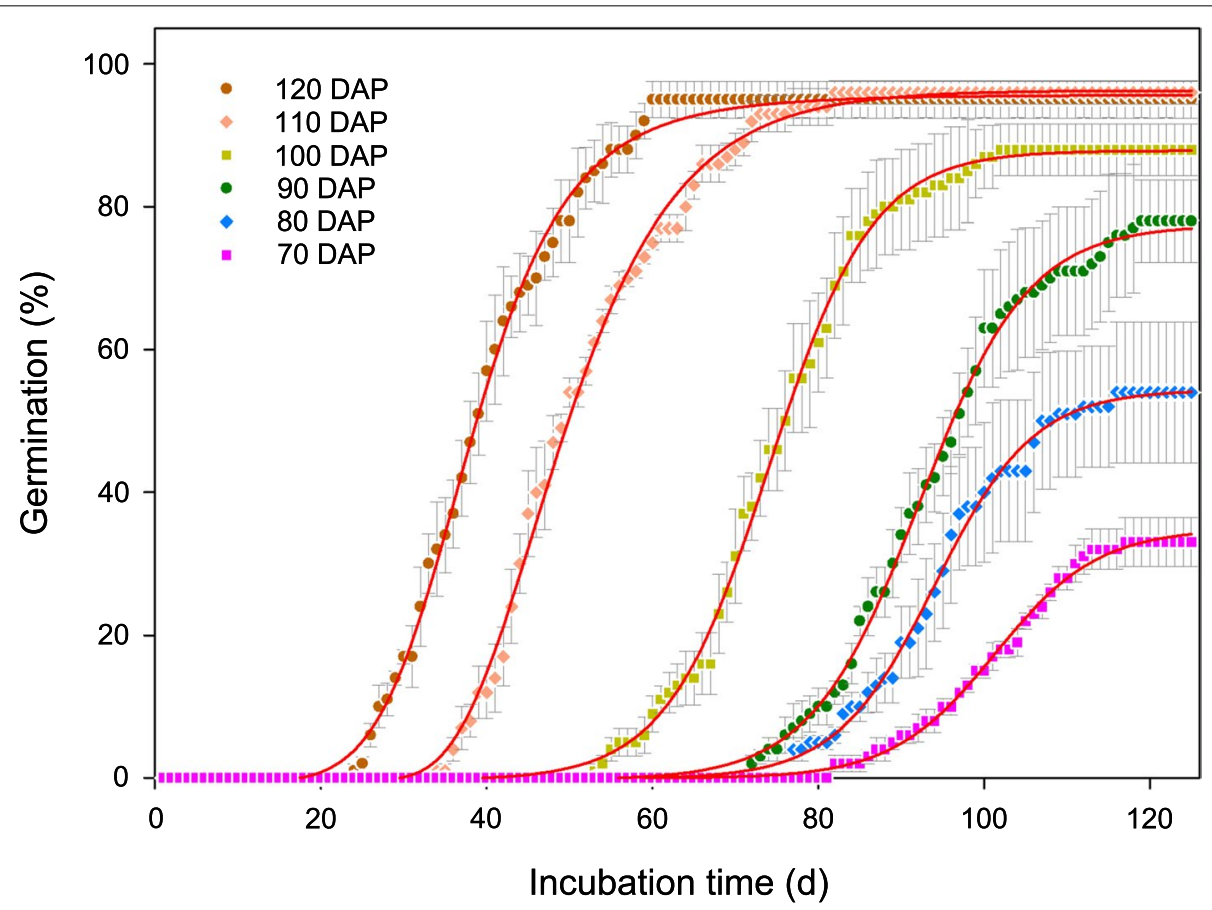

Fig. 4 Germination percentages of intact seeds of Paeonia ostii at different stages of development (mean \pm s.e.) 


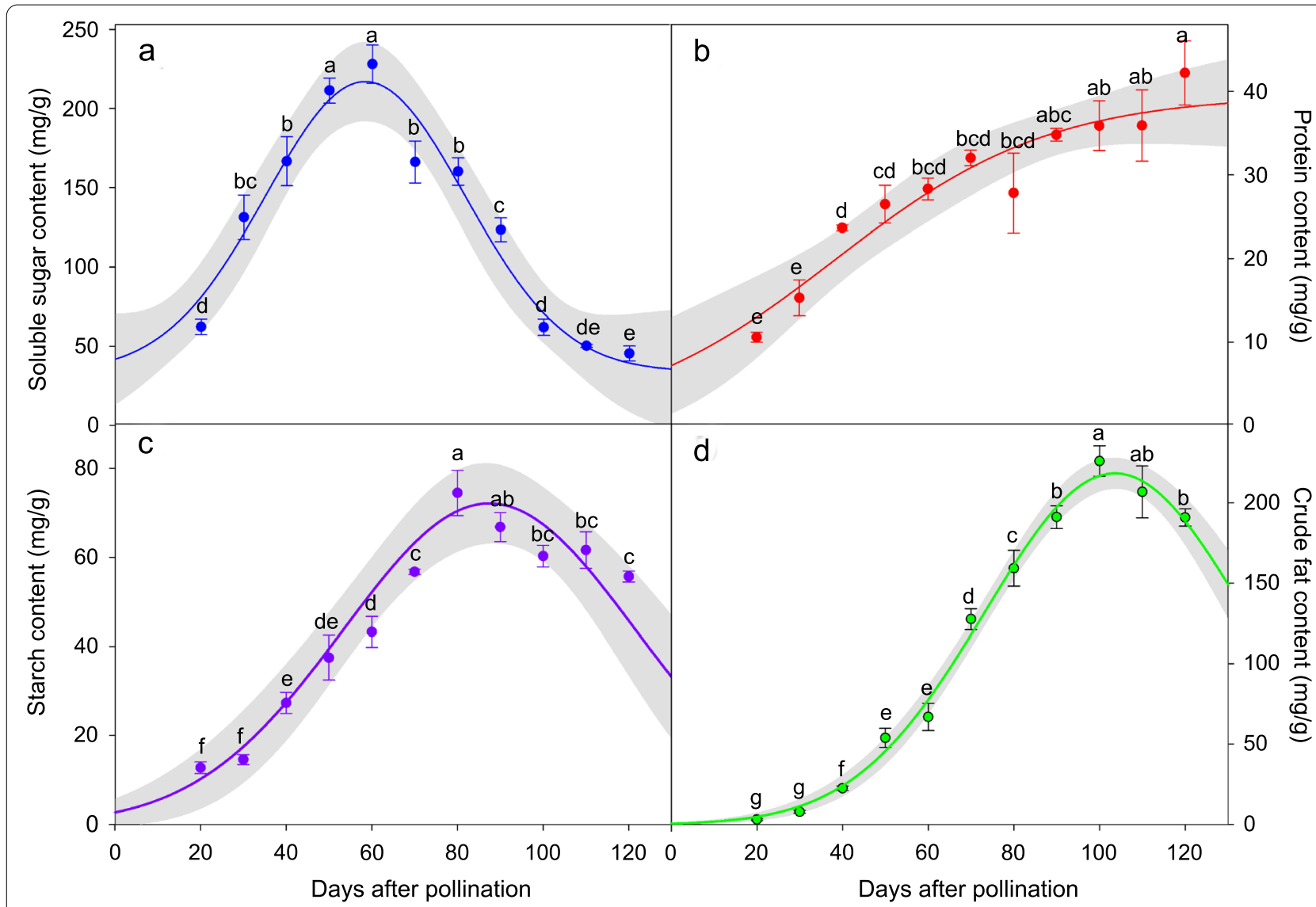

Fig. 5 (a) Soluble sugar, (b) protein, (c) starch and (d) crude fat content of developing seeds of Paeonia ostii (mean \pm s.e.). The solid line is a regression curve and the color band $95 \%$ confidence interval. Different letters indicate significant differences among different days after pollination $(P<0.05)$

size (Fig. 6d and g). By 10-15 DAP, these free nuclei are arranged peripherally within the proembryo, and the central vacuole fills the entire proembryo (Fig. 6e and f). By 20 DAP, small vacuoles begin to appear in the cytoplasm at the periphery of the proembryo (Fig. 6g). By 25 DAP, the proembryo begins to cellularize. The free nuclei in the outermost cytoplasm are separated by the periclinal wall, and there are still some free nuclei in the center of the proembryo (Fig. 6h). By 35 DAP, almost all of the free nuclei have formed a cell wall, the central vacuole has shrunk and the proembryo is a solid mass of cells (Fig. 7a). By 40 DAP, certain peripheral cells have divided, the margins of the proembryo are undulated at the surface and meristematic centers have formed, each of which has the potential to become an embryo primordium (Fig. 7b). At 45 DAP, only one embryonic protuberance has continued growing, and it forms a globular embryo; the other coenocytic structures have collapsed (Fig. 7c). Size of the proembryo gradually increases, becomes compressed and gradually disintegrates at 50 DAP (Fig. 7d).
By 55 DAP, two cotyledon primordia can be seen away from the chalazal side of the seed, and the embryo has become heart-shaped (Fig. 7e). Thereafter, the cotyledons differentiate rapidly, and the whole embryo undergoes extensive elongation and matures. By DAP 60, the embryo can be seen with the naked eye (Figs. 3 and $7 \mathrm{f}$ ). Thereafter, growth of the cotyledons is responsible for much of its increase in length, rather than growth of the axis. However, the leaf primordium does not appear until 90 DAP, when a bulge was observed between the two cotyledons (Fig. $7 \mathrm{~g}$ and $\mathrm{h}$ ). Thereafter, embryo morphogenesis is completed, and no further morphological change occurs.

Development of the P. ostii endosperm follows a typical nuclear type, whereby the primary endosperm nucleus divides without formation of a cell wall and ultimately produces a peripheral multinuclear endosperm tissue. Endosperm development occurs earlier than that of the embryo (Fig. 8a and b). The endosperm has 8 to 16 nuclei before the zygote divides. As the free nuclei of the endosperm repeatedly divide and proliferate, they are 

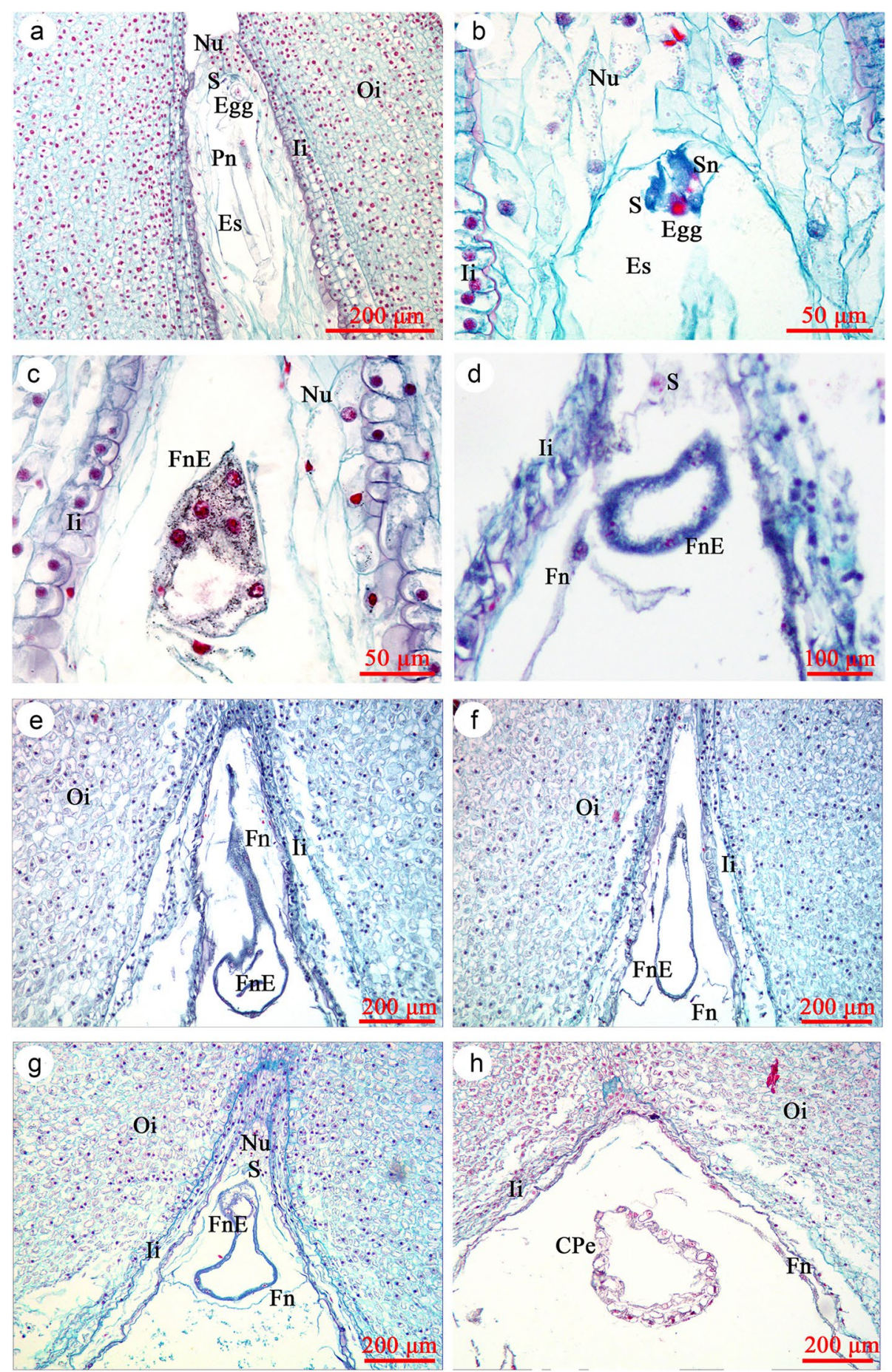

Fig. 6 Longitudinal sections of developing seeds of Paeonia ostii. (a) 0 DAP (ovule), (b) 3 DAP, (c) 7 DAP, (d) 9 DAP, (e) 13 DAP, (f) 15 DAP, (g) 20 DAP, (h) 25 DAP. CPe, cellularized proembryo; Egg, egg cell; Es, embryo sac; Fn, free nuclear endosperm; FnE, free nuclear proembryo; li, inner integument; $\mathrm{Nu}$, nucellus; Oi, outer integument; Pn, polar nucleus; S, synergid cell; Sn, sperm nucleus

gradually distributed at the periphery of inner integument (Fig. 6d, f and h). Cellarization of the free nuclei endosperm occurs between 30-35 DAP, which is later than that of the proembyo. Cell wall formation of the free nuclear endosperm is rapid, and it begins adjacent to the proembryo and spreads toward the chalazal end of 

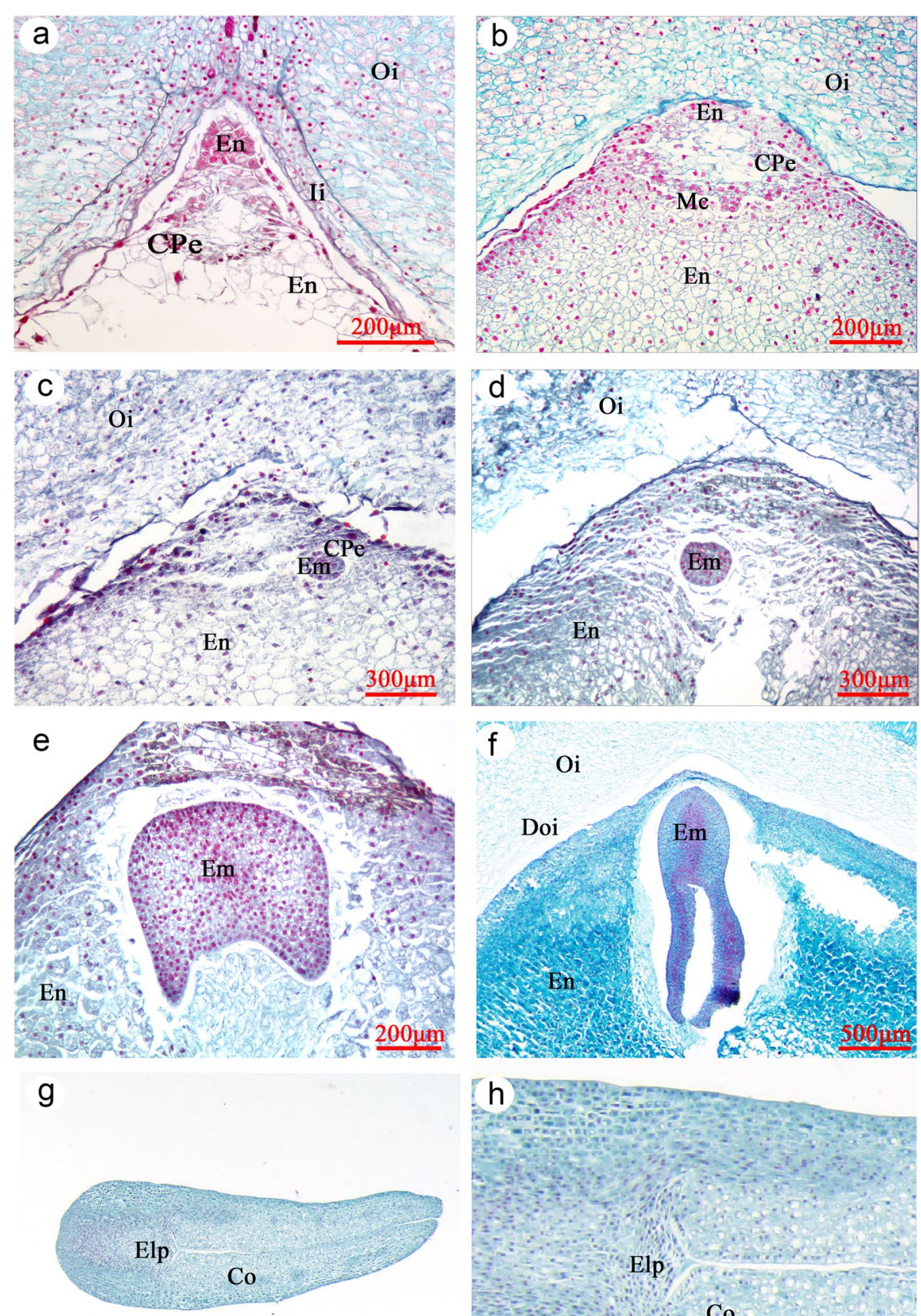

$500 \mu \mathrm{m}$

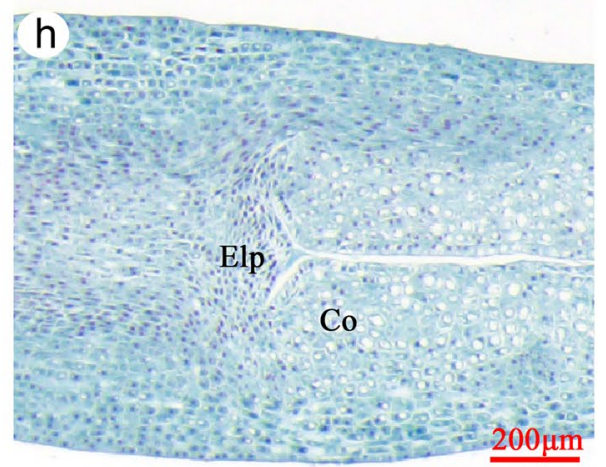

Fig. 7 Longitudinal sections of developing seeds of Paeonia ostii. (a) 35 DAP, (b) 40 DAP, (c) 45 DAP, (d) 50 DAP, (e) 55 DAP, (f) 60 DAP, (g and h) 90 DAP. Co, cotyledon; CPe, cellularized proembryo; Doi, degraded areas in outer integument; Elp, epicotyl leaf primordium; Em, embryo; En, endosperm cell; li, inner integument; Mc, meristematic centers of proembryo; Oi, outer integument

the seed (Fig. 7a). During cellularization, the endosperm gradually changed from liquid to colloidal state. The inner integument is gradually degraded and absorbed by the endosperm cells. By 40 DAP, all endosperm free nuclei form a cell wall (Fig. 7b), and no inner integument can be observed. Further, the inner layer of the outer 

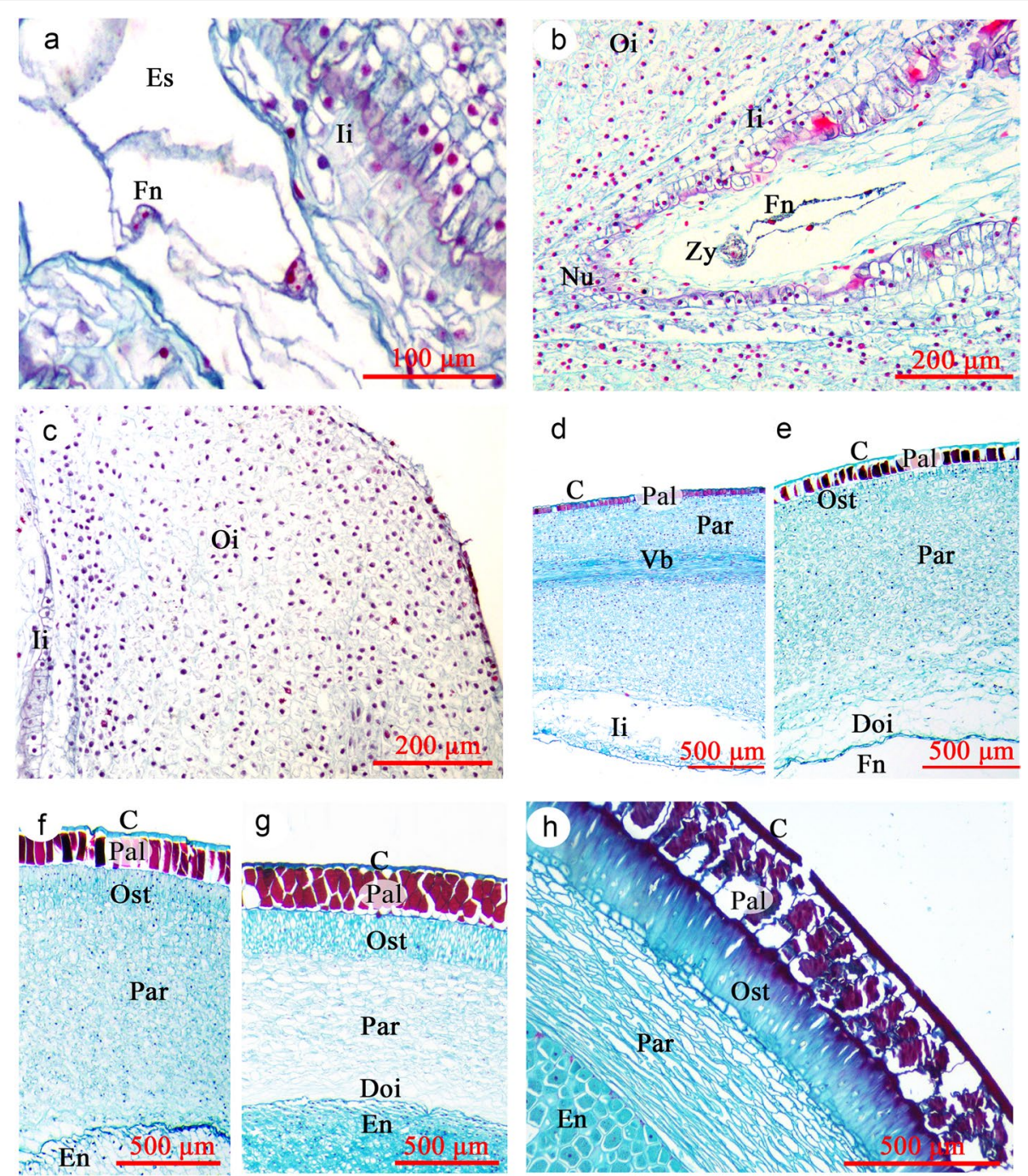

Fig. 8 Longitudinal sections of developing seeds of Paeonia ostii. (a) 3 DAP, (b) 5 DAP, (c) 9 DAP, (d) 20 DAP, (e) 30 DAP, (f) 35 DAP, (g) 45 DAP, (h) 120 DAP. C, cuticle; Doi, degraded areas in outer Integument; En, endosperm cell; Es, Embryo sac; Fn, Free nuclear endosperm; li, inner integument; Nu, Nucellus; Oi, outer integument; Ost, osteosclerid layers; Pal, palisade cell layers; Par, parenchyma cell layers; Vb, vascular bundle; Zy, zygote

integument gradually degrades, and a clear imprint of the degraded area of the outer integument was observed (Fig. 8g). From 50 DAP, inclusions in the endosperm cells gradually increased (Fig. 7d-f). By 65 DAP, the endosperm was solid, and the cells were full of inclusions (nutrition). Thereafter, the endosperm tissue gradually hardens and reaches a mature state.

The seed coat of $P$. ostii develops from the outer integument. During 1-10 DAP, the integument cells progressively grew with no obvious differentiation (Fig. 8c), while those of the outer integument divided periclinally, with thickest areas having more than 50 layers. Thus, the thickness of the seed coat increased. Thereafter, the outer epidermis grew periclinally, and a cuticle layer was observed above it. By 20 DAP, the epidermis was stained red by safranin, indicating that the cell wall had become lignified. Further, a palisade cell layer of macrosclerid cells had formed (Fig. 8d). A vascular bundle often was observed at the middle of the outer integument during development (Fig. 8d). As seeds developed, the inner integument gradually was absorbed by the endosperm (Fig. 7b). By 30 DAP, the layer beneath the palisade cell layer had elongated, forming the osteosclerid layer (Fig. 8e). As the endosperm cellularized, thickness of the seed coat gradually decreased, with the maximum thickness observed at 35 DAP. Prior to 45 DAP, when the endosperm changed to the colloidal state, the principal tissue of the developing seed was the seed 
coat (inner integument), which contributed most of the seed mass. Thereafter, the palisade and osteosclerid cell layers continued to elongate, and the seed coat could be divided into four distinct parts, which were (from outside to inside): cuticle and palisade, osteosclerid and parenchyma cell layers (Fig. $8 \mathrm{f}$ and g). Before seed dispersal, the parenchyma cells have contracted due to the compression on them by the developing endosperm (Fig. 8h).

\section{Discussion}

Cultivation of oilseed peony as a woody edible oil crop is currently in the early stages of development, and heretofore the precise temporal and spatial patterns of formation of the seed coat, endosperm and embryo were lacking. In this study, we present the results of a detailed account of the morphology/anatomy of seed development, accumulation of storage reserves and germinability of $P$. ostii seeds at various stages from fertilization to seed maturity.

\section{Growth and development of the $P$. ostii seeds}

Mature seeds of $P$. ostii consist of an embryo, endosperm and seed coat, with the endosperm occupying most of the volume inside the mature seed. Development of the embryo of $P$. ostii differs from that of all other angiosperms, but it is similar to that of gymnosperms (see below). Endosperm development of $P$. ostii follows the typical nuclear type (see Sreenivasulu and Wobus [22] for types of endosperm development). Cellarization of the free endosperm nuclei occurs later than that of the proembyo, which differs from $P$. californica in which the nuclei are cellarized at the same time [23]. The seed coat of $P$. ostii is derived from the outer integument, and during development its color changes from yellow to black.

Development of most orthodox (desiccation tolerant) seeds can be divided into three phrases: (I) early embryogenesis, (II) cell expansion and accumulation of stored reserves and (III) maturation drying. The duration of each of the major phases of development varies from several days to several months, depending on species and environmental conditions [4]. For instance, Geranium carolinianum seeds reached physiological maturity 14 DAP [24], Lotus ornithopodioides 54 DAP [25], Cypripedium formosanum 120 DAP [26], Ginkgo biloba 190 DAP [27] and Albizia lebbeck 230 DAP [28]. The time span of seed development in $P$. ostii from pollination to maturity was $125 \mathrm{~d}$. Seeds reached physiologically mature by 100 DAP, during which time dry matter content reached its maximum. The whole developmental process in P. ostii is longer than that reported for other peony species. For example, seeds of Paeonia rockii required 100 DAP from pollination to seed maturity, while those of P. lactiflora
'Hangshao' required 90 DAP, with seeds reaching physiologically mature by 70 DAP [29].

Early embryogenesis (phrase I), cell expansion and accumulation of stored reserves (phrase II) and maturation drying (phrase III) of P. ostii occurred 1-60, 21-100, and 101-125 DAP, respectively. These results are quite different from those of other well documented orthodox seeds, in which these three phrases are discrete and continuous. For example, in Arabidopsis thaliana and Glycine $\max$ [30] the embryo is globular, then heart-shaped and forms a 'linear cotyledon-shaped' embryo during phrase I, and the embryo axis and cotyledons are formed (differentiated) at the end of early embryogenesis [30], i.e., phrase I. However, in P. ostii, seed dry mass increased quickly from 20 DAP, indicating the start of synthesis and deposition of stored reserves, i.e. start of phrase II. However, at 20 DAP the embryo is not well differentiated and still in a coenocytic proembryo state; a 'linear cotyledon-shaped' embryo was not observed before 60 DAP. This indicates that the first two phases of embryo development overlapped. In phrase III, seed dry mass reached its maximum and remained constant, while fresh mass decreased, which may mean that seeds underwent an acute loss of water because of a loss of vascular supply to the seed [4]. However, we did not find an acute loss of water in seeds of $P$. ostii. We speculate that this may have been due to the accumulation of storage reserves in phrase II that consumed a large amount of water and thus masked the water loss. A displacement of water by insoluble reserves from cytoplasm is common during accumulation of storage reserves in the development of orthodox seeds [4].

\section{Embryogenesis}

Division of the zygote of $P$. ostii is not accompanied by cell wall formation, and according to available references a coenocytic proembryo is formed. These results are consistent with those of Yakovlev and Yoffe [31] for P. anomala, $P$. daurica subsp. wittmanniana (as $P$. wittmanniana) and P. suffruticosa (as P. moutan), and they agree with the report of Cave et al. [23] on P. californica and P. brownii and of Mu and Wang [32] on P. lactiflora. However, our results do not agree with those of Murgai [33] that the first division of the zygote nucleus is accompanied by cell wall formation and that the suspensor is coenocytic [33]. Prior to division of the zygote nucleus and even following the first several divisions, it appears that one synergid cell is pressed against the developing zygote. Thus, the twocell proembryo of Murgai [33] should be the surviving synergid cell that forms a unit with the zygote. In addition, we did not find an apical cell attached to the coenocytic proembryo. 
An extensive free-nuclear stage at the beginning of embryogeny is common among gymnosperms. Moreover, there is a trend in reduction of free nuclei in evolutionarily advanced gymnosperms [34, 35]. For example, some species of cycads can have more than $2^{10}$ (1024) free nuclei in the early stages of embryo development. In Ginkgo biloba (Ginkgoales), several hundred free nuclei are uniformly distributed in the embryo sac [36], while in Coniferales such as Picea and Pinus, the number of free nuclei is four [37]. In advanced gymnosperms such as Welwitschia and Gnetum (Gnetales), there is no free nuclear stage [34].

In $P$. ostii, cell wall formation follows the coenocytic condition. Several meristematic centers are formed among peripheral cells of the proembryo. These centers produce various protuberances (embryonal tubes), each representing an independently developing embryo. In most cases, only one of the protuberances survives and matures. Batygina [38] proposed the term "embryoidogeny", which she defined as the formation of somatic embryos in the flower and seed and on vegetative organs in situ, in vivo and in vitro, as a new category of vegetative propagation. In this regard, the mature embryo of $P$. ostii and other Paeonia species [23,31,32] is a somatic embryo, arising from epidermal cells of the zygote embryo. The zygote embryo degenerates during seed development. Specifically, the zygote embryo $(n+n)$ of P. ostii was observed before 45 DAP; thereafter, from 50 DAP a somatic embryo (embryoid, $2 \mathrm{n} \rightarrow 2 \mathrm{n}$ ) replaced the zygote embryo.

\section{Storage reserves}

Accumulation of storage reserves such as proteins, carbohydrates and lipids is an important aspect of seed maturation. These reserves support germination and the initial growth of seedlings [39]. In P. ostii, the main species in the genus used for peony oil production, accumulation of storage reserves is similar to that of the oil seeds of Arabidopsis thaliana [40], Brassica napus [41], Glycine $\max$ [42] and Sinapis alba [43]. Specifically, at the beginning of seed development soluble sugar and starch content increased because carbohydrates produced by photosynthesis were translocated to seeds, thus promoting the accumulation of soluble sugar and starch [4, 39]. Subsequently, soluble sugars and starch are broken down, since they function as precursors in oil and protein synthesis $[4,39]$. At the late stage of seed development, crude fat makes up the largest proportion of the reserves. Our results are consistent with those of Han et al. [15] who studied the effect of shading on nutrient accumulation of P. ostii. They found that soluble sugar and starch reached their maximum at 56 and 84 DAP, respectively, and that crude fat reached its maximum at 98 DAP. Zhao and $\mathrm{Wu}[44]$ also demonstrated that as seeds of P. ostii developed the number and size of the oil body increased. In P. lactiflora 'Hangshao' seeds, starch reached its maximum content at $60 \mathrm{DAP}$ and crude fat at 75 DAP. Further, the crude fat content of P. lactiflora 'Hangshao' is lower than that of P. ostii [29].

Another point that needs to be mentioned is the coordinated interactions between the endosperm and seed coat during development of $P$. ostii seeds. Prior to 45 DAP, the principal tissue of the developing seed was the inner integument (seed coat), which contributed most of the seed mass. Therefore, during seed development of $P$. ostii the seed coat acts as a temporary storage tissue of the seeds, and the main storage reserves of seed coat are soluble sugars and starch. As the seed develops (i.e. as the endosperm is cellularized), thickness of seed coat decreases, while the endosperm contributes most of the seed volume (mass). At this time, lipid and protein become the main storage reserves. However, the interconversion of the storage reserves between endosperm and seed coat needs to be explored further.

\section{Germinability}

Germinability of $P$. ostii seeds occurred 60-70 DAP, at which time $33 \%$ of them germinated. All seeds $\leq 60$ DAP rotted (without germinating) during incubation. Germination percentage increased with seed development, indicating that the vigor of the embryos had increased. Furthermore, as seeds developed germination rate (speed) increased. Seeds reached maximum dry mass at 100 DAP, while germination percentage and rate were lower than they were at 110 and 120 DAP. Abscisic acid (ABA) induces seed maturation and promotes dormancy, while gibberellins antagonise ABA and promote germination [45]. During seed development in P. ostii, ABA content gradually increased and reached its maximum value at 104 DAP and then decreased [46]. Thus, we speculate this is why the physiologically matured seeds (100 DAP) had lower germination percentage and speed than seeds of 110 and 120 DAP. However, little is known about the content of GA during development of P. ostii seeds [46].

\section{Conclusions}

The period of seed development in P. ostii from pollination to dispersal was $125 \mathrm{~d}$, with seeds becoming germinable at 60-70 DAP and physiologically mature by 100 DAP. Like other orthodox seeds, those of $P$. ostii can be divided into early embryogenesis (phrase I), cell expansion and accumulation of stored reserves (phrase II) and maturation drying (phrase III). However, they differ from most other well-documented orthodox seeds, in which these three phrases are discrete and continuous. The first two phrases of $P$. ostii overlapped at $1-60$ and 
21-100 DAP. Loss of a large amount of water was not observed in phrase III. This possibly was due to accumulation of storage reserves in phrase II, which consumed a large amount of water, thus masking the water loss. Development of the embryo of $P$. ostii is similar to that reported for other peony species but differs from that which normally occurs in angiosperms. The development of $P$. ostii seeds and accumulation of storage reserves are summarized in Fig. 9. The ovule of $P$. ostii is crassinucellate and bitegmic. The inner integument is 2-4 cell layers thick and the outer integument $14-20$ cell layers thick. The seed coat of P. ostii is derived from the outer integument. Endosperm development in $P$. ostii follows a typical nuclear type of development and is persistent. Embryo development can be divided into two stages: a coenocytic proembryo from zygote $(n+n)$, and a somatic sexual embryo from peripheral cells of proembryo (embryoid, $2 n \rightarrow 2 n$ ). During seed development, the seed coat acts as a temporary storage tissue of the seeds. As the seed develops, the thickness of seed coat decreases. However, the interconversion of

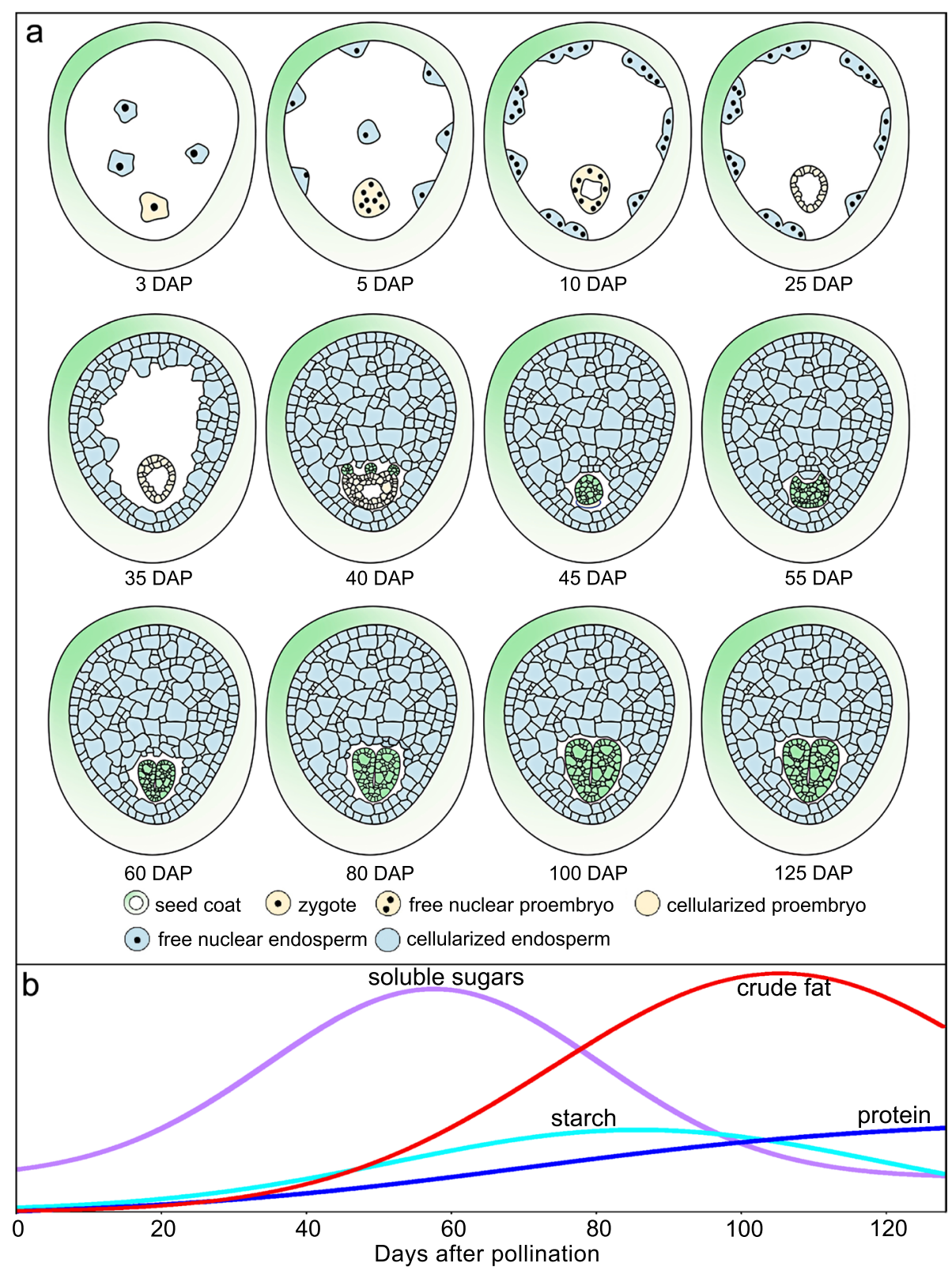

Fig. 9 Summary of (a) seed development and (b) storage reserves in Paeonia ostii 
the storage reserves between endosperm and seed coat needs to be explored further.

\section{Methods \\ Study site and seed collection}

Plants of $P$. ostii used in this study were about 10 -years old and were growing in a 0.3 ha experimental garden on the campus of Yangzhou University. Plants in this garden were owned by ourselves, which permit us unrestricted use. The plants used in this study were identified by Jun Tao from the Key Laboratory of Crop Genetics and Physiology of Jiangsu Province. To ensure seed set, flowers were hand cross-pollinated [47] in early April of 2018 and 2020. Then, every pollinated flower was tagged so that the pollination date was known. Fruits were collected on different days after pollination (DAP). The collected material was placed in ZipLoc plastic bags and taken to the laboratory immediately. Developing seeds used in all experiments were collected in 2018, except those used for determination of soluble sugars, starch, protein and crude fat content, which were collected in 2020.

\section{Seed morphology, fresh mass, dry mass and water content} during development

Forty ovules/seeds (hereafter seeds) were separated from fruits collected at 5-day intervals between 0-125 DAP. Ten seeds (randomly-chosen from those 40 seeds) were used to measure seed length, width and thickness using a dissecting microscope and image analysis software for 0-35 DAP and a vernier caliper 40-125 DAP, after which seeds were photographed with a digital camera 40-125 DAP. Then, all 40 seeds were divided into four groups (i.e. four replicate of 10 seeds), and each group was weighed (fresh mass), oven-dried, weighed (dry mass) and water content calculated.

\section{Embryo morphology of developing seeds}

To monitor morphological changes during seed development, 10 embryos were isolated from developing seeds harvested at 5-day intervals from 60-120 DAP using a razor blade. Then, embryo length and seed length were measured using a dissecting microscope and image analysis software. Embryo (E): seed (S) length ratios were calculated. The extremely small embryos at 0-55 DAP could not be seen by the naked eye.

\section{Germination of developing seeds}

Four replicates of 25 seeds separated from fruits collected at 10-day intervals from 0-120 DAP were placed in 10-cm diameter Petri dishes on two layers of filter paper moistened with $5 \mathrm{~mL}$ distilled water and incubated at
$15 / 25^{\circ} \mathrm{C}$ in $12 / 12 \mathrm{~h}$ dark/light conditions. Cool white fluorescent tubes provided ca. $100 \mu \mathrm{mol} / \mathrm{m}^{2} / \mathrm{s}$ photon irradiance $(400-700 \mathrm{~nm})$ to seeds. Germination was checked daily for 125 days, and the criterion for germination was emergence of a radicle tip of $\geq 1 \mathrm{~mm}$. Germinated seeds were counted and removed from the Petri dishes.

\section{Soluble sugars, starch, protein and crude fat content of developing seeds}

The anthrone- $\mathrm{H}_{2} \mathrm{SO}_{4}$ colorimetric method was used to measure soluble sugar and starch content in the developing seeds [48]. Developing seeds were collected at 10-day intervals 20-120 DAP. After being ground and homogenized with $10 \mathrm{~mL}$ deionized water, $200 \mathrm{mg}$ samples were put into a boiling water bath for $20 \mathrm{~min}$. After being cooled to room temperature, the homogenate was centrifuged twice at $6000 \mathrm{rpm}$ for $10 \mathrm{~min}$ at $15{ }^{\circ} \mathrm{C}$. The supernatant was collected for determination of soluble sugar content at $630 \mathrm{~nm}$ via a UV spectrophotometer (Bluestar A, LabTech Ltd., Beijing, China). The residue was homogenized in $10 \mathrm{~mL}$ of deionized water and $2 \mathrm{~mL}$ of $52 \%$ perchloric acid for determination of starch spectrophotometrically at $630 \mathrm{~nm}$ [48].

Soluble protein content was assayed using the Coomassie brilliant blue G-250 method [48]. First, a Coomassie brilliant blue G-250 and standard protein solutions were prepared. One-half gram of fresh seeds was ground with $10 \mathrm{~mL}$ distilled water using a mortar and pestle. After centrifugation of the solution at $4000 \times \mathrm{g}$ for $10 \mathrm{~min}$, the supernatant was transferred to a clean tube and total protein content measured as the change in absorbance at $595 \mathrm{~nm}[48]$.

Crude fat was determined by the Soxhlet extractor method [48]. One gram of developing seeds was ground and placed into a 50-mL Soxhlet extractor with an extraction time of $4 \mathrm{~h}$ in $100 \mathrm{~mL}$-hexane. Then, peony seed oil was extracted by distilling the $n$-hexane mixture in a rotary evaporator. The content of crude fat was calculated as described in [48].

\section{Anatomical changes in seeds during development}

Ten developing seeds were collected at 2-day intervals from 0 (immediately before pollination) to $18 \mathrm{DAP}$ and at 5-day intervals 20 and 110 DAP. The seeds were fixed in FAA (formalin: glacial acetic acid: $50 \%$ ethanol $=5: 5: 90$ by volume) for $24 \mathrm{~h}$. Then, they were dehydrated sequentially in $50 \%, 70 \%, 85 \%, 95 \%$ and $100 \%$ ethanol for $1 \mathrm{~h}$ in each concentration. Next, $100 \%$ ethanol was added to each sample for $1 \mathrm{~h}$, after which samples were transferred sequentially to $25,50,75$ and $100 \%$ tertiary-butanol for $4 \mathrm{~h}$ in each concentration. Then, each sample was embedded in paraffin wax and kept at ambient laboratory conditions until used. Finally, $6 \mu \mathrm{m}$ longitudinal sections of 
the seed coat and pericarp were cut transversely using a microtome (RM2235, Leica Microsystems Inc., Heidelberg, Germany) and stained with $1 \%$ safranin followed by $2 \%$ fast green solutions. Observations and photography were carried out with a light microscope (Olympus CX31, Olympus Corp., Tokyo, Japan) and MShot 9.0 image analysis software (Micro-shot Corp., Shanghai, China).

\section{Statistical analysis}

To evaluate the distribution pattern of seed length, width, thickness, water content, dry mass, fresh mass, soluble protein, soluble sugars, starch and crude fat during seed development, Linear, Gompertz, Hill, Logistic, Sigmoid, Gaussian and Weibull functions were used to fit the data in Sigmaplot ver. 12.0. The equation with the highest adjusted $r^{2}$ was selected. Germination percentage data were normalized by arcsine-transformation and analyzed by one-way analysis of variance and Duncan's multiple range test in Statistica ver. 13 (Statsoft, Inc, Tulsa, OK, USA).

\section{Supplementary Information}

The online version contains supplementary material available at https://doi. org/10.1186/s12870-021-03373-z.

Additional file 1: Table S1. Selected models fitted to seed length, width, thickness, dry mass, fresh mass, water content, starch, soluble protein, soluble sugar and crude fat.

\section{Acknowledgements}

The authors thank Dr. Yanhong Yang and Yusong Ji for excellent technical assistance.

\section{Authors' contributions}

K.Z., J.S. and J.T. conceived and designed the research. W.C. L.Y. carried out the morphological and histological studies. K.Z. wrote the first draft of the manuscript. JMB and CCB revised several drafts of the manuscript. All authors read and approved the final manuscript.

\section{Funding}

This work was supported by the National Natural Science Foundation of China (Grant No. 31800340), and the Jiangsu Forestry Science and Technology Innovation and Promotion Project of China (Grant No. (LYKJ[2018]41)). The funding organizations provided financial support to the research projects, but were not involved in the design of the study, data collection, analysis of the data or writing of the manuscript.

\section{Availability of data and materials}

The data generated or analyzed in this study are included in this article and its supplementary information files. Other materials that support the findings of this study are available from the corresponding author on reasonable request.

\section{Declarations}

Ethics approval and consent to participate

Not applicable
Consent for publication

Not applicable

\section{Competing interests}

The authors declare that they have no competing interests.

\section{Author details}

${ }^{1}$ College of Horticulture and Plant Protection, Yangzhou University, Yangzhou 225009, China. ${ }^{2}$ Joint International Research Laboratory of Agriculture and Agri-Product Safety, The Ministry of Education of China, Yangzhou University, Yangzhou 225009, China. ${ }^{3}$ Department of Biology, University of Kentucky, Lexington, KY 40506, USA. ${ }^{4}$ Department of Plant and Soil Sciences, University of Kentucky, Lexington, KY 40546, USA. ${ }^{5}$ Department of Plant Engineering, Jiangsu Union Technical Institute, Huai-An 223200, China.

Received: 19 May 2021 Accepted: 1 December 2021

Published online: 18 December 2021

\section{References}

1. Chaudhury AM, Koltunow A, Payne T, Luo M, Peacock WJ. Control of early seed development. Annu Rev Cell Develop Biol. 2001;17:677-99. https:// doi.org/10.1146/annurev.cellbio.17.1.677.

2. Hamamura Y, Nagahara S, Higashiyama T. Double fertilization on the move. Curr Opin Plant Biol. 2012;15:70-7. https://doi.org/10.1016/j.pbi. 2011.11.001.

3. Gehring M, Satyaki PR. Endosperm and imprinting, inextricably linked. Plant Physiol. 2017;173:143-54. https://doi.org/10.1104/pp.16.01353.

4. Bewley JD, Bradford KJ, Hilhorst HWM, Nonogaki H. Seeds. Physiology of development, germination and dormancy. 3rd ed. New York: SpringerVerlag; 2014. https://doi.org/10.1007/978-1-4614-4693-4.

5. Kubitzki K. The Families and Genera of Vascular Plants, vol. 4. Berlin Heidelberg: Springer-Verlag; 2007.

6. Sang T, Crawford DJ, Stuessy TF. Chloroplast DNA phylogeny, reticulate evolution, and biogeography of Paeonia (Paeoniaceae). Am J Bot. 1997:84:1120-36. https://doi.org/10.2307/2446155.

7. Kamenetsky R, Dole J. Herbaceous peony (Paeonia): genetics, physiology and cut flower production. Floric Ornam Plant Biotech. 2012;6:62-77.

8. Parker S, May B, Zhang C, Zhang A, Lu C. Xue C A pharmacological review of bioactive constituents of Paeonia lactiflora Pallas and Paeonia veitchii Lynch. Phytother Res. 2016;30:1445-73. https://doi.org/10.1002/ptr.5653.

9. Ministry of Health of the People's Republic of China. Announcement No. 9. 2011; 2: 264 (in Chinese).

10. Barceló-Coblijn G, Murphy J. Alpha-linolenic acid and its conversion to longer chain n-3 fatty acids: benefits for human health and a role in maintaining tissuen-3 fatty acid levels. Prog Lipid Res. 2009;48:355-74. https://doi.org/10.1016/j.plipres.2009.07.002

11. Zhang X, Shi Q, Ji D, Niu L, Zhang Y. Determination of the phenolic content, profile, and antioxidant activity of seeds from nine tree peony (Paeonia, section Moutan DC.) species native to China. Food Res Int. 2017;97:141-8. https://doi.org/10.1016/j.foodres.2017.03.018.

12. Jing $X$, Zheng $G$. The characteristics in seed germination and dormancy of four wild species of tree peonies and their bearing on endangerment. Acta Phytophysiol Sin. 1999:25:214-21.

13. Zhang K, Yao L, Zhang Y, Baskin JM, Baskin CC, Xiong Z, Tao J. A review of the seed biology of Paeonia species (Paeoniaceae) with particular reference to dormancy and germination. Planta. 2019;249:291-303. https:// doi.org/10.1007/s00425-018-3017-4

14. Zhang K, Pan H, Baskin CC, Baskin JM, Xiong ZM, Cao WZ, Yao LJ, Tang B, Zhang C, Tao J. Epicotyl morphophysiological dormancy in seeds of Paeonia ostii (Paeoniaceae): Seasonal temperature regulation of germination phenology. Environ Exp Bot. 2022;194:104742. https://doi.org/10.1016/j. envexpbot.2021.104742.

15. Han C, Wang Q, Zhang H, Wang S, Song H, Hao J, Dong H. Light shading improves the yield and quality of seed in oil-seed peony (Paeonia osti Feng Dan). J Integr Agric. 2019;17:1631-40. https://doi.org/10.1016/ S2095-3119(18)61979-3.

16. Liu P, Zhang L, Wang X, Gao J, Yi J, Deng R. Characterization of Paeonia ostii seed and oil sourced from different cultivation areas in China. Ind Crop Prod. 2019;133:63-71. https://doi.org/10.1016/j.indcrop.2019.01.054. 
17. Peng LP, Men SQ, Liu ZA, Tong NN, Imran M, Shu QY. Fatty acid composition, phytochemistry, antioxidant activity on seed coat and kernel of Paeonia ostii from main geographic production areas. Foods. 2020;9:30. https://doi.org/10.3390/foods9010030.

18. Li SS, Yuan RY, Chen LG, Wang LS, Hao XH, Wang LJ, Zheng XC, Du H. Systematic qualitative and quantitative assessment of fatty acids in the seeds of 60 tree peony (Paeonia section Moutan DC.) cultivars by GC-MS. Food Chem. 2015;173:133-40. https://doi.org/10.1016/j.foodchem.2014. 10.017.

19. Lv S, Cheng S, Wang Z, Li S, Jin X, Lan L, et al. Draft genome of the famous ornamental plant Paeonia suffruticosa. Ecol Evol. 2020;10:4518-30. https:// doi.org/10.1002/ece3.5965.

20. Li S, Wang L, Shu Q, Wu J, Chen L, Shao S, Yin D. Fatty acid composition of developing tree peony (Paeonia section Moutan DC.) seeds and transcriptome analysis during seed development. BMC Genomics. 2015;16:208. https://doi.org/10.1186/s12864-015-1429-0.

21. Wang X, Liang H, Guo D, Duan X, Jia Q, Hou X. Integrated analysis of transcriptomic and proteomic data from tree peony (P. ostii) seeds reveals key developmental stages and candidate genes related to oil biosynthesis and fatty acid metabolism. Hortic Res. 2019;6:1-19. https://doi.org/10. 1038/s41438-019-0194-7.

22. Sreenivasulu N, Wobus U. Seed-development programs: a systems biology-based comparison between dicots and monocots. Annu Rev Plant Biol. 2013;64:189-217. https://doi.org/10.1146/annurev-arpla nt-050312-120215.

23. Cave MS, Arnott HJ, Cook SH. Embryology in the California peonies with reference to their taxonomic position. Am J Bot. 1961;48:397-404. https:// doi.org/10.1002/j.1537-2197.1961.tb11657.x.

24. Gama-Arachchige NS, Baskin JM, Geneve RL, Baskin CC. Acquisition of physical dormancy and ontogeny of the micropyle-water-gap complex in developing seeds of Geranium carolinianum (Geraniaceae). Ann Bot. 2011;108:51-64. https://doi.org/10.1093/aob/mcr103.

25. Gresta F, Avola G, Onofri A, Anastasi U, Cristaudo A. When does hard coat impose dormancy in legume seeds: Lotus and Scorpiurus case study. Crop Sci. 2011;51:1739-47. https://doi.org/10.2135/cropsci2010.12.0700.

26. Lee YI, Lee N, Yeung EC, Chung MC. Embryo development of Cypripedium formosanum in relation to seed germination in vitro. J Am Soc Hort Sci. 2005;130:752-3. https://doi.org/10.21273/JASHS.130.5.747.

27. Feng J, Shen Y, Shi F, Li C. Embryo development, seed germination, and the kind of dormancy of Ginkgo biloba L. Forests. 2018;9:700. https://doi. org/10.3390/f9110700.

28. Uniyal RC, Nautiyal AR. Physiobiochemical aspects of development of hardseededness in Albizia lebbek. Curr Sci. 1995;69:358-60.

29. Meng JS. Observation of seed development and excavation of genes related to lipid accumulation for herbaceous peony (Paeonia lactiflora Pall. 'Hangshao'). Yangzhou: Yangzhou University; 2019. (Ph.D. dissertation)

30. Lin J, Le B, Chen M. Similarity between soybean and Arabidopsis seed methylomes and loss of non-CG methylation does not affect seed development. Proc Natl Acad Sci USA. 2017;1 14:e9730-9. https://doi.org/10. 1073/pnas. 1716758114

31. Yakovlev MS, Yoffe MD. On some peculiar features in the embryology of Paeonia L. Phytomorphology. 1957:7:74-82.

32. MuXJ, Wang FX. The early development of embryo and endosperm of Paeonia lactiflora. Acta Bot Sin. 1995;87:7-12 (plus plates I, 2 (in Chinese)).

33. Murgai P. The development of the embryo in Paeonia - a reinvestigation. Phytomorphology. 1959;9:275-7.

34. Chowdhury CR. The embryogeny of conifers: a review. Phytomorphology. 1962;12:313-38. https://doi.org/10.1111/j.1467-1770.1962.tb01268.x.

35. Wang FX, Chen ZQ. A contribution to the embryology of Ginkgo with a discussion of the affinity of the Ginkgoales. Acta Bot Sin. 1983;25:199-207.

36. Wang L, Wang D, Lin M, LuY, Jiang $X$, Jin B. An embryological study and systematic significance of the primitive gymnosperm Ginkgo biloba. J Syst Evol. 2011;49:353-61. https://doi.org/10.1111/j.1759-6831.2011.00123.x.

37. Attree SM, Fowke LC. Embryogeny of gymnosperms: advances in synthetic seed technology of conifers. Plant Cell Tiss Org. 1993;35:1-35. https://doi.org/10.1007/BF00043936.

38. Batygina TB. Embryoidogeny - a new category of reproduction in flowering plants. In: Teryokhin ES, editor. Problems of Reproductive Biology of
Seed Plants. Saint-Petersburg: Komarov Botanical Institute of the Russian Academy of Sciences; 1993. p. 15-25 (in Russian).

39. Borisjuk L, Rolletschek H, Wobus U, Weber H. Differentiation of legume cotyledons as related to metabolic gradients and assimilate transport into seeds. J Exp Bot. 2003;54:503-12. https://doi.org/10.1093/jxb/erg051.

40. Baud S, Boutin JP, Miquel M, Lepiniec L, Rochat C. An integrated overview of seed development in Arabidopsis thaliana ecotype WS. Plant Physiol Biochem. 2002;40:151-60. https://doi.org/10.1016/S0981-9428(01) 01350-X.

41. da Silva PMFR, Eastmond PJ, Hill LM, Smith AM, Rawsthorne S. Starch metabolism in developing embryos of oilseed rape. Planta. 1997;203:480-7. https://doi.org/10.1007/s004250050217.

42. Yazdi-Samadi B, Rinne RW, Seif RD. Components of developing soybean seeds: oil, protein, sugars, starch, organic acids, and amino acids 1. Agron J. 1977;69:481-6. https://doi.org/10.2134/agronj1977.000219620069000 $30037 x$.

43. Fischer W, Schopfer P. Isolation and characterization of mustard (Sinapis alba L.) seed storage proteins. Bot Acta. 1988;101:48-56. https://doi.org/ 10.1111/j.1438-8677.1988.tb00011.x.

44. Zhao M, Wu S. Seed development and oil body dynamics of tree peony. Trees. 2020;34:721-9. https://doi.org/10.1007/s00468-020-01952-5.

45. Graeber K, Nakabayashi K, Miatton E, Leubner-Metzger G, Soppe WJ. Molecular mechanisms of seed dormancy. Plant Cell Environ. 2012;35:1769-86. https://doi.org/10.1111/j.1365-3040.2012.02542.x

46. Xue J, Wang S, Zhang P, Zhu F, Ren X, Liu C, Zhang X. On the role of physiological substances, abscisic acid and its biosynthetic genes in seed maturation and dormancy of tree peony (Paeonia ostii 'Feng Dan'). Sci Hortic. 2015;182:92-101. https://doi.org/10.1016/j.scienta.2014.11.021.

47. Xin H, Cheng FY, Xiao JJ, Wang YL, Zhong Y. Crosses of Paeonia ostii'Feng Dan Bai' as maternal parents and an analysis on the potential in tree peony breeding. J Beijing For Univ. 2014;36:121-5 (In Chinese).

48. Li HS. Principle and Technology of Plant Physiological and Biochemical Experiments. Beijing: Higher Education Press; 2000.

\section{Publisher's Note}

Springer Nature remains neutral with regard to jurisdictional claims in published maps and institutional affiliations.

Ready to submit your research? Choose BMC and benefit from:

- fast, convenient online submission

- thorough peer review by experienced researchers in your field

- rapid publication on acceptance

- support for research data, including large and complex data types

- gold Open Access which fosters wider collaboration and increased citations

- maximum visibility for your research: over 100M website views per year

At BMC, research is always in progress.

Learn more biomedcentral.com/submissions 